Article

\title{
Exposure to Indoor Volatile Organic Compounds and Hypertension among Thin Film Transistor Liquid Crystal Display Workers
}

\author{
Ta-Yuan Chang ${ }^{1, *(D)}$, Kuei-Hung Huang ${ }^{1}$, Chiu-Shong Liu ${ }^{2}$ and Bo-Ying Bao ${ }^{3,4}$ (D) \\ 1 Department of Occupational Safety and Health, College of Public Health, China Medical University, \\ Taichung 40402, Taiwan; rachelsun0212@gmail.com \\ 2 Department of Family Medicine, China Medical University Hospital, Taichung 40402, Taiwan; \\ liucs@ms14.hinet.net \\ 3 Department of Pharmacy, College of Pharmacy, China Medical University, Taichung 40402, Taiwan; \\ bao@mail.cmu.edu.tw \\ 4 Department of Nursing, Asia University, Taichung 40402, Taiwan \\ * Correspondence: tychang@mail.cmu.edu.tw; Tel.: +886-4-22053366 (ext. 6203)
}

Received: 1 June 2020; Accepted: 1 July 2020; Published: 6 July 2020

\begin{abstract}
This cross-sectional study aimed to determine the concentration of indoor volatile organic compounds (VOCs) and to investigate the association between indoor VOCs exposure and the prevalence of hypertension among thin film transistor liquid crystal display (TFT-LCD) workers. A total of 20 canisters were used to collect VOCs samples in the array, cell and module areas over 12 hours and VOCs concentrations were analyzed by the gas chromatography with mass spectrum. Individual information of health examination and lifestyles by self-administrated questionnaire were provided by 155 volunteers. The multivariate regression models were used to evaluate the associations between VOCs exposure, blood pressure and the prevalence of hypertension. The four dominant VOCs were ethanol (1870.8 $\pm 1754.0 \mathrm{ppb})$, acetone (689.9 $\pm 587.4 \mathrm{ppb})$, isopropyl alcohol $(177.1 \pm 202.3 \mathrm{ppb})$ and propylene glycol monomethyl ether acetate $(98.2 \pm 100.8 \mathrm{ppb})$, which were identified with the highest level in the module area for ethanol and acetone and in the array area for the others. Subjects exposed to a total level of ethanol, cyclohexanone and toluene $\geq 2500 \mathrm{ppb}$ had an increased systolic blood pressure of $5.95 \mathrm{mmHg}$ (95\% confidence interval: $0.20-11.71 ; p=0.043$ ) compared with those exposed to $<2500 \mathrm{ppb}$. Exposure to mixed VOCs in the indoor environment might be associated with elevated blood pressure among TFT-LCD workers.
\end{abstract}

Keywords: exposure assessment; hypertension; thin film transistor liquid crystal display; volatile organic compounds

\section{Introduction}

The manufacturing of thin film transistor liquid crystal display (TFT-LCD) is one of the important industries worldwide, and many digital or electrical products use the TFT-LCD as a panel or monitor, such as personal computers, laptops, televisions, mobile phones, tablets and handheld video game systems. A research report by IMARC Group estimated that the global TFT-LCD panel market was valued at more than US\$ 149 billion in 2018 and anticipated to reach US\$ 208.6 billion by 2024 [1].

The emission of volatile organic compounds (VOCs) occurs in the production of TFT-LCD panels, which involves three major groups of array, cell and module assembly processes. The array process fabricates the transistors on a glass substrate, the cell process joins the arrayed substrate to the color-filter substrate filling with liquid crystal between the two spaces and the module assembly process connects additional components (i.e., driver-integrated circuits and backlight units) to the fabricated glass 
panel. Some components of VOCs have been determined in the indoor environment during these manufacturing processes, such as acetone, ethanol, ethyl acetate, isopropyl alcohol, propylene glycol monomethyl ether (PGME), propylene glycol monomethyl ether acetate (PGMEA) and toluene [2-4].

Many studies have reported the associations between some VOCs exposure and increased blood pressure. A cohort study demonstrated a relationship between alcohol consumption ( $>120 \mathrm{~g} /$ week, equal to $4556 \mathrm{ppb}$ under the assumption of $20 \mathrm{~m}^{3} /$ day for inhalation rates at $25^{\circ} \mathrm{C}$ and $760 \mathrm{mmHg}$ ) and elevated ambulatory systolic blood pressure (SBP) among 248 subjects [5]. In an in vivo study, the enhanced vasoreactivity to vasoactive hormones was found to contribute the development of hypertension induced by ethanol consumption in Sprague-Dawley rats [6]. An animal study observed the pulmonary hypertension and elevated vascular resistance after the cyclohexanone instillation [7]. In occupational epidemiological studies, exposure to toluene at a high level of 40-1200 ppm [8] or in the range of 0.4-216 ppm for more than 20 years [9] was found to be associated with increased SBP in printing workers. Since single exposure to ethanol, cyclohexanone and toluene was observed to be associated with elevated blood pressure, it is interesting to test whether the synergistic effect existed in workers co-exposed to these three VOCs.

Some studies have reported the adverse health effects due to VOCs exposure among TFT-LCD workers, however the associations between indoor VOCs exposure and blood pressure have not yet been explored. One field study reported a decreased prevalence of urinary tract infection after performing an intervention program among clean-room females working in the TFT-LCD industry [10]. Another cross-sectional study found that workers cumulatively exposed to a total level of isopropyl alcohol, PGMEA and PGME $\geq 324$ ppb-year might have a risk of kidney dysfunction [4]. The purpose of this study was to determine the concentration of indoor VOCs and to investigate the association between indoor VOCs exposure and the prevalence of hypertension in TFT-LCD workers.

\section{Materials and Methods}

\subsection{Subjects}

We performed this study in a TFT-LCD manufacturing plant with 2162 employees during March-June in 2007. Only 1686 clean-room workers were included to avoid significant differences in the indoor environment compared with 476 non-clean-room workers at work. One-third of the proportion of total clean-room workers were invited as potential participants due to three shift works and only 562 daytime-shift workers were recruited from three major processes, including 170 array workers, 280 cell workers and 112 module workers. However, only 155 employees were willing to provide individual health-check results and demographic information for analysis in this study. No significant differences in age, employment duration, body mass index (BMI), cigarette smoking, alcohol drinking, tea consumption and regular exercise collected from a self-administered questionnaire were identified between the 155 participants and 407 non-participants. Before commencement, the study protocol was reviewed and approved by the Institutional Review Board of the College of Public Health, China Medical University, and each participant provided written informed consent.

\subsection{Blood Pressure Measurements and Hypertension Definition}

During this company's annual health-check examinations in 2007, all participants were informed to fast overnight before blood sampling and blood pressure measurements were obtained the next day. Subjects sat for $10 \mathrm{~min}$ in a back-supported chair with both feet flat on the floor and their arms supported at heart level during blood pressure measurements. A trained nurse measured each subject's bilateral blood pressure using an automated sphygmomanometer (Ostar Model P2, Ostar Meditech Corp., Taipei, Taiwan) in the morning before work. The mean of two measurements was used to represent an individual's SBP and diastolic blood pressure (DBP), respectively. We defined a hypertensive case if a participant reported a medical diagnosis of hypertension by a physician or the use of antihypertensive medication indicated in the questionnaire, if he/she had a mean resting 
$\mathrm{SBP} \geq 140 \mathrm{mmHg}$ or if he/she had a mean resting DBP $\geq 90 \mathrm{mmHg}$ during the annual examinations in 2007.

Height, body weight, total cholesterol level, triglyceride level, high-density lipoprotein (HDL) and low-density lipoprotein (LDL) cholesterol levels were also measured in all participants. The body weight $(\mathrm{kg})$ was divided by the square of height $\left(\mathrm{m}^{2}\right)$ to calculate the BMI.

In addition, a self-administered questionnaire was used to collect potential confounders and effect modifiers during the study period, including age, employment duration, cigarette smoking, alcohol drinking, tea consumption, coffee consumption, regular exercise and a family history of hypertension. Cigarette smokers were defined as those who had smoked cigarettes on more than 3 days per week for at least 6 months; alcohol, tea and coffee drinkers were defined by the same criterion. Regular exercisers were defined as those who had participated in a sporting activity at least 3 times per week for 6 months or more.

\subsection{Volatile Organic Compounds Exposure Assessment}

We performed a comprehensive walk-through survey to recognize hazardous zones of total VOC levels in the clean room using a pocket photo-ionization detector (PMG-30, RAE System Inc., San Jose, CA, USA). The 20 workstations determined with the highest concentrations of total VOCs were further subjected to 12-hour time-weighted-average VOCs sampling during working periods, including 12 locations in the array process, 5 locations in the cell process, and 3 locations in the module process.

We followed the U.S. Environmental Protection Agency Compendium Method TO-15 [11] to sample and analyze VOCs levels. A 6-L SUMMA stainless steel canister with a silonite-coated valve (29-10622G model, Entech Instruments Inc., Simi Valley, CA, USA) was used to obtain air samples at a flow rate of $8.4 \mathrm{~mL} \mathrm{~min}^{-1}$. An injection volume of $100 \mathrm{~mL}$ for VOCs collected in the canister was concentrated in a cryogenic concentrator (ENTECH 7100A, Entech Instruments Inc.) and was injected into a gas-chromatograph (HP6890, Agilent Technologies Inc., Santa Clara, CA, USA) coupled to a mass-selective detector (HP5973, Agilent Technologies Inc.). A capillary column (J\&W DB-502.2, $60 \mathrm{~m} \times 0.25 \mathrm{~mm} \times 1.4 \mu \mathrm{m}$, J\&W Scientific, Folsom, CA, USA) was used in this system for analysis. The laboratory and field blanks, parallel samples and duplicate measurements of samples were applied to quality assurance $(\mathrm{QA})$ and quality control $(\mathrm{QC})$ procedures. The analyzed VOCs showed that detection limits ranged from $0.4 \mu \mathrm{g} \mathrm{m}^{-3}$ (ethanol) to $0.9 \mu \mathrm{g} \mathrm{m}^{-3}$ (PGMEA). The recovery rates of all VOCs analyzed were between $96.2 \%$ (acetone) and $101.1 \%$ (m/p-xylene) with the relative standard deviations ranging from 1.4\% (PGMEA) to $7.0 \%$ (acetone). The operational conditions of the gas-chromatograph/mass spectrometry system, VOC analyses and QA/QC procedures in detail have been mentioned in previous studies $[4,12,13]$. All participants were categorized into 1 of 20 workstations based on the indoor concentrations of VOCs measured at work with similar exposure to VOCs.

\subsection{Statistical Analysis}

We used the Kruskal-Wallis test for continuous variables and the Chi-square test (or Fisher's exact test) for dichotomous variables to perform multiple comparisons among the three groups [14]. For those variables revealing significant differences between groups, the Mann-Whitney test and the Chi-square test were applied to compare continuous variables and dichotomous variables for the two groups [14]. Because participants' blood pressure measurements and VOCs exposure were not distributed normally, Spearman correlation coefficients were performed to evaluate the correlations between SBP, DBP and each component of VOCs levels.

In order to examine the association between VOCs exposure and hypertension, those VOCs correlated positively with both SBP and DBP were summed to calculate the mixed levels of VOCs exposure for each subject. The third quartile (75th percentile) in the distribution of the mixed 
levels of VOCs was selected as the cut-off value to classify participants into the high-exposure and low-exposure groups.

We used logistic regression models to estimate the odds ratios (ORs) and 95\% confidence intervals (CIs) [14] in order to compare between-group differences in the prevalence of hypertension. Model 1 was a simple logistic regression for all candidate variables. Model 2 was adjusted for significant variables associated with the risk of hypertension in model 1. The final model (model 3) extended model 2 with significantly different variables between three major-process groups (i.e., array, cell and module). In addition, the generalized linear regressions were applied to investigate the associations of mixed exposure to VOCs with SBP and DBP adjusting for potential confounders and effect modifiers [14]. All statistical analyses were performed using the SAS standard package for Windows version 9.1 (SAS Institute Incorporation, Cary, NC, USA). We set up the significance level at 0.05 for all tests.

\section{Results}

Table 1 shows demographic characteristics of 155 participants by study group. Significant differences were identified in the mean values of age and HDL cholesterol, the percentage of male subjects and the proportion of regular exercisers between the three groups (all $p$ values $>0.05$ ). The cell group had a significantly higher mean age than that in the array and module groups $(p<0.05)$. In contrast, the module workers had a higher mean HDL cholesterol compared with the cell workers $(p<0.05)$. Both array and cell groups had significantly higher proportions of male subjects and regular exercisers than those in the module group (both $p$ values $<0.05$ ). The three groups did not have significant differences in terms of employment duration, total cholesterol, triglyceride, LDL cholesterol, cigarette smoking, alcohol drinking, tea consumption and coffee consumption (all $p$ values $>0.05$ ).

Table 1. Demographic characteristics of participants by group.

\begin{tabular}{|c|c|c|c|c|c|}
\hline \multirow{2}{*}{ Characteristic } & \multicolumn{3}{|c|}{ Study Group } & \multirow{2}{*}{$\begin{array}{l}\text { Total Subjects } \\
\quad(n=155)\end{array}$} & \multirow{2}{*}{$p$-Value } \\
\hline & Array $(n=66)$ & Cell $(n=67)$ & Module $(n=22)$ & & \\
\hline Age (years), Mean \pm SD & $27.2 \pm 3.2^{b}$ & $28.4 \pm 2.9^{c}$ & $26.5 \pm 2.7$ & $27.6 \pm 3.0$ & $0.008^{a}$ \\
\hline $\begin{array}{l}\text { Employment duration (years), } \\
\text { Mean } \pm \text { SD }\end{array}$ & $3.3 \pm 2.3$ & $3.0 \pm 1.4$ & $4.0 \pm 2.1$ & $3.3 \pm 2.0$ & $0.524^{\mathrm{a}}$ \\
\hline $\begin{array}{c}\text { Body Mass Index }\left(\mathrm{kg} \mathrm{m}^{-2}\right) \\
\text { Mean } \pm \text { SD }\end{array}$ & $22.9 \pm 3.1$ & $23.4 \pm 3.4$ & $21.5 \pm 2.3$ & $22.9 \pm 3.2$ & $0.063^{\mathrm{a}}$ \\
\hline $\begin{array}{c}\text { Total cholesterol }\left(\mathrm{mg} \mathrm{dL}^{-1}\right) \\
\text { Mean } \pm \text { SD }\end{array}$ & $192.9 \pm 33.5$ & $196.2 \pm 31.7$ & $186.4 \pm 21.1$ & $193.6 \pm 31.4$ & $0.295^{\mathrm{a}}$ \\
\hline $\begin{array}{c}\text { Triglyceride }\left(\mathrm{mg} \mathrm{dL}^{-1}\right) \\
\text { Mean } \pm \mathrm{SD}\end{array}$ & $102.2 \pm 95.3$ & $107.2 \pm 65.4$ & $74.6 \pm 33.9$ & $101.0 \pm 77.5$ & $0.093^{a}$ \\
\hline $\begin{array}{l}\text { HDL cholesterol }\left(\mathrm{mg} \mathrm{dL}^{-1}\right), \\
\text { Mean } \pm \text { SD }\end{array}$ & $48.1 \pm 13.1$ & $46.1 \pm 12.0^{\mathrm{c}}$ & $53.4 \pm 10.4$ & $47.9 \pm 12.5$ & $0.045^{\mathrm{a}}$ \\
\hline $\begin{array}{l}\text { LDL cholesterol }\left(\mathrm{mg} \mathrm{dL}^{-1}\right) \\
\text { Mean } \pm \text { SD }\end{array}$ & $127.1 \pm 31.2$ & $129.7 \pm 31.0$ & $115.2 \pm 20.6$ & $126.7 \pm 30.1$ & $0.206^{\mathrm{a}}$ \\
\hline Gender, male (\%) & $46(69.7)^{f}$ & $56(83.6)^{f}$ & $3(13.6)$ & $105(67.7)$ & $<0.001^{\mathrm{d}}$ \\
\hline Smoker, yes (\%) & $8(12.1)$ & $12(17.9)$ & $1(4.6)$ & $21(13.6)$ & $0.256^{\mathrm{d}}$ \\
\hline Alcohol drinking, yes (\%) & $1(1.5)$ & $4(6.0)$ & $0(0.0)$ & $5(3.2)$ & $0.396^{\mathrm{e}}$ \\
\hline Tea consumption, yes (\%) & $26(39.4)$ & $28(41.8)$ & $8(36.4)$ & $62(40.0)$ & $0.895^{\mathrm{d}}$ \\
\hline Coffee consumption, yes (\%) & $21(31.8)$ & $21(31.3)$ & $6(27.3)$ & $48(31.0)$ & $0.920^{\mathrm{d}}$ \\
\hline Regular exercise, yes (\%) & $27(40.9)^{f}$ & $30(44.8)^{f}$ & $2(9.1)$ & $59(38.1)$ & $0.009^{d}$ \\
\hline $\begin{array}{c}\text { Family history of } \\
\text { hypertension, yes (\%) }\end{array}$ & $24(36.4)$ & $14(20.9)$ & $6(27.3)$ & $44(28.4)$ & $0.140^{\mathrm{d}}$ \\
\hline
\end{tabular}

HDL: high-density lipoprotein; LDL: low-density lipoprotein; SD: standard deviation. ${ }^{\text {a }}$ Kruskal-Wallis test of differences between groups. ${ }^{\mathrm{b}}$ Mann-Whitney test of significant difference $(p<0.05)$ compared with the cell group. ${ }^{c}$ Mann-Whitney test of significant difference $(p<0.05)$ compared with the module group. ${ }^{\mathrm{d}}$ Chi-square test of

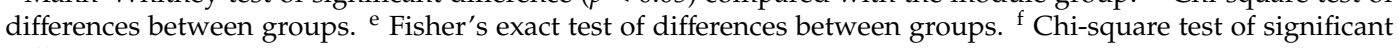
difference $(p<0.05)$ compared with the module group.

Table 2 summarizes the indoor concentrations of VOCs measured in the clean room for the three groups. Ethanol $(1870.8 \pm 1754.0 \mathrm{ppb})$, acetone $(689.9 \pm 587.4 \mathrm{ppb})$, isopropyl alcohol $(177.1 \pm 202.3 \mathrm{ppb})$ and PGMEA $(98.2 \pm 100.8 \mathrm{ppb})$ were the four VOCs present at the highest levels out of a total of 
12 components identified in the workplace with at least $85 \%$ environmental samples (i.e., $\mathrm{n}=17$ ) measured above detection limits. There were significant differences in the mean levels of ethanol, acetone, isopropyl alcohol, PGMEA, cyclohexanone, toluene, m/p-xylene, o-xylene, 1,2,4-trimethylbenzene, benzaldehyde and 1-ethyl-3-methylbenzene between the three groups. Both array and cell groups had significantly higher mean levels of isopropyl alcohol, PGMEA and benzaldehyde but lower mean levels of ethanol, acetone, cyclohexanone and toluene than those in the module group (all $p$ values $<0.05$ ). Subjects in the array workstations exposed to significantly higher mean levels of $\mathrm{m} / \mathrm{p}$-xylene, o-xylene, 1,2,4-trimethylbenzene and 1-ethyl-3-methylbenzene compared with those in the cell and module workstations (all $p$ values $<0.05$ ). In contrast, the cell group had significantly lower levels of $\mathrm{m} / \mathrm{p}$-xylene, o-xylene, 1,2,4-trimethylbenzene and 1-ethyl-3-methylbenzene than the module group (all $p$ values $<0.05$ ). Only the mean level of hexane was not significantly different between the three groups ( $p$ value $>0.05)$.

Table 2. Mean values \pm stand deviation of exposure levels of volatile organic compounds (VOCs) by study group.

\begin{tabular}{|c|c|c|c|c|c|c|}
\hline \multirow[b]{2}{*}{ Chemical } & \multirow[b]{2}{*}{ CASRN } & \multirow{2}{*}{$\begin{array}{c}\text { Array } \\
\text { Mean } \pm \text { SD } \\
(p p b)\end{array}$} & \multirow{2}{*}{$\begin{array}{c}\text { Cell } \\
\begin{array}{c}\text { Mean } \pm \text { SD } \\
(p p b)\end{array}\end{array}$} & \multirow{2}{*}{$\begin{array}{c}\text { Module } \\
\begin{array}{c}\text { Mean } \pm \text { SD } \\
(p p b)\end{array}\end{array}$} & \multirow{2}{*}{$\begin{array}{c}\text { Total Subjects } \\
\text { Mean } \pm \text { SD (ppb) }\end{array}$} & \multirow[b]{2}{*}{$p$-Value } \\
\hline & & & & & & \\
\hline Ethanol & $64-17-5$ & $667.1 \pm 370.0^{b, c}$ & $2624.1 \pm 2065.5^{b}$ & $3188.1 \pm 739.1$ & $1870.8 \pm 1754.0$ & $<0.001^{a}$ \\
\hline Acetone & $67-63-0$ & $587.6 \pm 42.9^{b, c}$ & $339.3 \pm 175.7^{b}$ & $2064.4 \pm 152.5$ & $689.9 \pm 587.4$ & $<0.001^{\mathrm{a}}$ \\
\hline $\begin{array}{l}\text { Isopropyl } \\
\text { alcohol }\end{array}$ & $67-64-1$ & $382.5 \pm 123.7^{b, c}$ & $32.5 \pm 82.4^{\mathrm{b}}$ & $1.7 \pm 0.6$ & $177.1 \pm 202.3$ & $<0.001^{\mathrm{a}}$ \\
\hline PGMEA & $108-65-6$ & $204.2 \pm 53.9^{b, c}$ & $25.7 \pm 33.3^{b}$ & $0.9 \pm 0.1$ & $98.2 \pm 100.8$ & $<0.001^{\mathrm{a}}$ \\
\hline Cyclohexanone & $108-94-1$ & $7.5 \pm 1.0^{b}$ & $7.5 \pm 4.8^{b}$ & $16.8 \pm 8.0$ & $8.8 \pm 5.4$ & $<0.001^{\mathrm{a}}$ \\
\hline Toluene & $108-88-3$ & $4.7 \pm 1.1^{b, c}$ & $5.9 \pm 3.3^{b}$ & $18.6 \pm 4.8$ & $7.2 \pm 5.5$ & $<0.001^{\mathrm{a}}$ \\
\hline $\mathrm{m} / \mathrm{p}$-Xylene & $\begin{array}{l}108-38-3 / \\
106-42-3\end{array}$ & $6.6 \pm 3.3^{b, c}$ & $3.7 \pm 1.5^{b}$ & $6.5 \pm 0.9$ & $5.3 \pm 2.7$ & $<0.001^{\mathrm{a}}$ \\
\hline o-Xylene & $95-47-6$ & $4.3 \pm 0.5^{b, c}$ & $1.6 \pm 0.9^{b}$ & $3.1 \pm 0.5$ & $3.0 \pm 1.4$ & $<0.001^{a}$ \\
\hline $\begin{array}{l}1,2,4- \\
\text { Trimethylbenzene }\end{array}$ & $95-63-6$ & $5.0 \pm 0.6^{b, c}$ & $0.6 \pm 0.9^{b}$ & $1.8 \pm 0.1$ & $2.6 \pm 2.2$ & $<0.001^{\mathrm{a}}$ \\
\hline Hexane & $110-54-3$ & $2.2 \pm 1.6$ & $1.8 \pm 1.4$ & $2.4 \pm 1.9$ & $2.1 \pm 1.5$ & $0.803^{c}$ \\
\hline Benzaldehyde & $100-52-7$ & $2.0 \pm 0.4^{b, c}$ & $0.8 \pm 0.2^{b}$ & $0.1 \pm 0.2$ & $1.2 \pm 0.8$ & $<0.001^{\mathrm{a}}$ \\
\hline $\begin{array}{l}\text { 1-Ethyl-3- } \\
\text { methylbenzene }\end{array}$ & $620-14-4$ & $1.4 \pm 0.2^{b, c}$ & $0.1 \pm 0.3^{b}$ & $0.7 \pm 0.1$ & $0.7 \pm 0.6$ & $<0.001^{\mathrm{a}}$ \\
\hline
\end{tabular}

CASRN: chemical abstracts service registry number; PGMEA: propylene glycol monomethyl ether acetate; SD: standard deviation. ${ }^{\text {a }}$ Kruskal-Wallis test of differences between groups. ${ }^{b}$ Mann-Whitney test of significant difference $(p<0.05)$ compared with the module group. ${ }^{c}$ Mann-Whitney test of significant difference $(p<0.05)$ between the array and cell groups.

The blood pressure measurements, prevalence of hypertension and the crude risk by study group are presented in Table 3. Only the cell workers had a significantly higher mean of SBP than that in the array workers $(p<0.05)$. The prevalence of hypertension was greater in the cell group (19.4\%) than in the array $(12.1 \%)$ and module $(9.1 \%)$ groups, however the result did not reach a significance level of 0.05 . Compared with the module group, the crude OR for hypertension was 1.38 (95\% CI: 0.27-7.05) in the array group and 2.41 (95\% CI: $0.50-11.63$ ) in the module group. Similarly, the risk of hypertension was not significant statistically.

Table 4 reveals the Spearman correlation coefficients between the indoor concentrations of VOCs and blood pressure measurements. Only three components of ethanol, cyclohexanone and toluene were positively correlated with both SBP and DBP, although the results did not reach significance (all $p$ values $>0.05$ ). The concentrations of these three components were summed to a mixed level for determining the association between the prevalence of hypertension and blood pressure measurements. 
Table 3. Prevalence of hypertension and crude odds ratios (ORs) (95\% CIs) by study group.

\begin{tabular}{cccccc}
\hline \multirow{2}{*}{ Group } & \multirow{2}{*}{ Number } & $\begin{array}{c}\text { Systolic Blood } \\
\text { Pressure }\end{array}$ & $\begin{array}{c}\text { Diastolic Blood } \\
\text { Pressure }\end{array}$ & $\begin{array}{c}\text { Prevalence of } \\
\text { Hypertension }\end{array}$ & Crude OR (95\% CI) \\
\cline { 3 - 5 } & & Mean \pm SD (mmHg) & Mean \pm SD (mmHg) & & \\
\hline Array & 66 & $118.3 \pm 14.5^{\mathrm{b}}$ & $74.1 \pm 10.3$ & $8(12.1)$ & $1.38(0.27-7.05)$ \\
Cell & 67 & $124.3 \pm 15.4$ & $76.0 \pm 11.2$ & $13(19.4)$ & $2.41(0.50-11.63)$ \\
Module & 22 & $122.2 \pm 14.6$ & $75.9 \pm 11.6$ & $2(9.1)$ & 1.0 \\
\hline$p$-value & & $0.093^{\mathrm{a}}$ & $0.579^{\mathrm{a}}$ & $0.356^{\mathrm{c}}$ & \\
\hline
\end{tabular}

95\% CI: 95\% confidence interval; OR: odds ratio; SD: standard deviation. ${ }^{\text {a }}$ Kruskal-Wallis test of differences between groups. ${ }^{\mathrm{b}}$ Mann-Whitney test of significant difference $(p<0.05)$ compared with the cell group. ${ }^{\mathrm{c}}$ Chi-square test of differences between groups.

Table 4. Correlation coefficients between specific VOCs levels and blood pressure.

\begin{tabular}{ccccc}
\hline \multirow{2}{*}{ Concentration (ppb) } & \multicolumn{2}{c}{ SBP (mmHg) } & \multicolumn{2}{c}{ DBP (mmHg) } \\
\cline { 2 - 5 } & Coefficients & $p$-Value ${ }^{\mathbf{a}}$ & Coefficients & $p$-Value $^{\mathbf{a}}$ \\
\hline Ethanol & 0.031 & 0.703 & 0.070 & 0.388 \\
Acetone & -0.115 & 0.153 & -0.050 & 0.540 \\
Isopropyl alcohol & -0.110 & 0.171 & -0.089 & 0.272 \\
PGMEA & -0.061 & 0.453 & -0.050 & 0.535 \\
Cyclohexanone & 0.095 & 0.238 & 0.093 & 0.250 \\
Toluene & 0.063 & 0.439 & 0.090 & 0.265 \\
m/p-Xylene & 0.041 & 0.613 & -0.002 & 0.977 \\
o-Xylene & -0.146 & 0.070 & -0.050 & 0.536 \\
1,2,4-Trimethylbenzene & -0.140 & 0.083 & -0.054 & 0.508 \\
Hexane & -0.084 & 0.296 & -0.080 & 0.320 \\
Benzaldehyde & -0.142 & 0.077 & -0.080 & 0.324 \\
1-Ethyl-3-methylbenzene & 0.131 & 0.105 & -0.059 & 0.463 \\
\hline
\end{tabular}

SBP: systolic blood pressure; DBP: diastolic blood pressure; PGMEA: propylene glycol monomethyl ether acetate. a Spearman correlation test.

The associations between workstation groups and the risk of hypertension are shown in Table 5. Only the gender and total cholesterol levels were significantly associated with the risk of hypertension in the simple logistic regressions (model 1). These two variables were combined with two exposure variables (i.e., array vs. module and cell vs. module) to establish a multivariate logistic regression (model 2). None of these four variables were significantly associated with the risk of hypertension (all $p$ values $>0.05$ ). Other three variables of age, HDL cholesterol and regular exercise that were significantly different between the three groups were added to model 2 for establishing an extended model (model 3) as the final model. The results did not reveal significant associations between workstation groups and the risk of hypertension after adjusting for potential confounders and effect modifiers (both $p$ values $>0.05$ ).

Table 6 presents the associations between VOCs exposure, blood pressure and the risk of hypertension. Subjects co-exposed to a total level of ethanol, cyclohexanone and toluene $\geq 2500 \mathrm{ppb}$ (the third quartile) were found to have an increased SBP of $5.95 \mathrm{mmHg}$ (95\% CI: $0.20-11.71 ; p=0.043$ ) compared with those co-exposed to a total level $<2500 \mathrm{ppb}$ after controlling for potential confounders and effect modifiers. Such a total level of VOCs among TLT-LCD workers also had a higher mean of DBP $(2.74 \mathrm{mmHg} ; 95 \% \mathrm{CI}:-1.45-6.92 ; p=0.198)$ and a greater risk of hypertension $(\mathrm{OR}=1.25 ; 95 \% \mathrm{CI}$ : $0.39-3.98 ; p=0.710$ ) than the low-exposure workers; however, the results were not found significantly in statistics (both $p$ values $>0.05$ ). 
Table 5. Associations between groups and the risk of hypertension using logistic regression models.

\begin{tabular}{|c|c|c|c|c|c|c|}
\hline \multirow{2}{*}{ Variable } & \multicolumn{2}{|c|}{ Model 1 ${ }^{a}$} & \multicolumn{2}{|c|}{ Model $2^{b}$} & \multicolumn{2}{|c|}{ Model $3^{c}$} \\
\hline & OR $(95 \% \mathrm{CI})$ & $p$-Value & OR $(95 \% \mathrm{CI})$ & $p$-Value & OR $(95 \% \mathrm{CI})$ & $p$-Value \\
\hline Group: Array vs. module & $1.38(0.27-7.05)$ & 0.699 & $0.63(0.10-4.14)$ & 0.623 & $0.65(0.10-4.31)$ & 0.655 \\
\hline Cell vs. module & $2.41(0.50-11.63)$ & 0.274 & $0.96(0.15-6.32)$ & 0.967 & $0.99(0.15-6.52)$ & 0.987 \\
\hline Gender, male vs. female & $3.69(1.04-13.06)$ & 0.043 & $3.57(0.80-15.86)$ & 0.095 & $3.45(0.70-16.94)$ & 0.127 \\
\hline Age (years), $\geq 30$ vs. $<30$ & $2.07(0.77-5.61)$ & 0.151 & & & $1.19(0.40-3.50)$ & 0.755 \\
\hline BMI $\left(\mathrm{kg} \mathrm{m}^{-2}\right), \geq 27$ vs. $<27$ & $1.16(0.24-5.68)$ & 0.853 & & & & \\
\hline $\begin{array}{c}\text { Total cholesterol }\left(\mathrm{mg} \mathrm{dL}^{-1}\right), \\
\geq 200 \text { vs. }<200\end{array}$ & $2.60(1.06-6.40)$ & 0.038 & $2.43(0.97-6.07)$ & 0.058 & $2.38(0.93-6.10)$ & 0.070 \\
\hline $\begin{array}{l}\text { Triglyceride }\left(\mathrm{mg} \mathrm{dL}^{-1}\right) \\
\geq 150 \text { vs. }<150\end{array}$ & $2.60(0.95-7.16)$ & 0.064 & & & & \\
\hline $\begin{array}{l}\text { HDL cholesterol }\left(\mathrm{mg} \mathrm{dL}^{-1}\right), \\
<40 \text { vs. } \geq 150\end{array}$ & $1.39(0.57-3.42)$ & 0.471 & & & $1.08(0.42-2.82)$ & 0.869 \\
\hline $\begin{array}{c}\text { LDL cholesterol }\left(\mathrm{mg} \mathrm{dL}^{-1}\right) \\
\geq 130 \text { vs. }<130\end{array}$ & $2.04(0.84-4.98)$ & 0.118 & & & & \\
\hline Smoker, yes vs. no & $2.75(0.94-8.06)$ & 0.065 & & & & \\
\hline Alcohol drinking, yes vs. no & $1.46(0.16-13.63)$ & 0.742 & & & & \\
\hline Tea consumption, yes vs. no & $1.18(0.48-2.90)$ & 0.712 & & & & \\
\hline $\begin{array}{l}\text { Coffee consumption, } \\
\text { yes vs. no }\end{array}$ & $1.90(0.77-4.71)$ & 0.164 & & & & \\
\hline Regular exercise, yes vs. no & $1.30(0.53-3.20)$ & 0.563 & & & $0.89(0.33-2.38)$ & 0.811 \\
\hline $\begin{array}{l}\text { Family history of } \\
\text { hypertension, yes vs. no }\end{array}$ & $1.12(0.43-2.95)$ & 0.814 & & & & \\
\hline
\end{tabular}

Table 6. Associations between VOCs exposure, blood pressure and the risk of hypertension.

\begin{tabular}{|c|c|c|c|c|c|c|}
\hline \multirow[b]{2}{*}{ Variable } & \multicolumn{2}{|l|}{ Model $1^{a}$} & \multicolumn{2}{|l|}{ Model $2^{a}$} & \multicolumn{2}{|c|}{ Model $3^{b}$} \\
\hline & $\begin{array}{c}\text { Increase in SBP } \\
(\mathrm{mmHg})(95 \% \mathrm{CI})\end{array}$ & $p$-Value & $\begin{array}{l}\text { Increase in DBP } \\
(\mathrm{mmHg})(95 \% \mathrm{CI})\end{array}$ & $p$-Value & OR $(95 \% \mathrm{CI})$ & $p$-Value \\
\hline $\begin{array}{l}\text { Total level of ECT (ppb) } \\
\geq 2500 \text { vs. }<2500\end{array}$ & $5.95(0.20-11.71)$ & 0.043 & $2.74(-1.45-6.92)$ & 0.198 & $1.25(0.39-3.98)$ & 0.710 \\
\hline Gender, male vs. female & $10.65(4.70-16.60)$ & $<0.001$ & $4.78(0.45-9.10)$ & 0.031 & $3.54(0.82-15.27)$ & 0.090 \\
\hline Age (years), $\geq 30$ vs. $<30$ & $-2.00(-8.19-4.19)$ & 0.525 & $1.94(-2.57-6.44)$ & 0.397 & $1.20(0.40-3.57)$ & 0.741 \\
\hline $\begin{array}{c}\text { Total cholesterol }\left(\mathrm{mg} \mathrm{dL}^{-1}\right), \\
\geq 200 \text { vs. }<200\end{array}$ & $4.40(-0.48-9.28)$ & 0.077 & $3.91(0.36-7.46)$ & 0.031 & $2.38(0.93-6.13)$ & 0.071 \\
\hline $\begin{array}{l}\text { HDL cholesterol }\left(\mathrm{mg} \mathrm{dL}^{-1}\right), \\
<40 \text { vs. } \geq 150\end{array}$ & $-1.81(-6.95-3.33)$ & 0.488 & $0.71(-3.03-4.45)$ & 0.709 & $1.06(0.40-2.79)$ & 0.909 \\
\hline Regular exercise, yes vs. no & $-0.50(-5.60-4.61)$ & 0.848 & $-1.38(-5.09-2.33)$ & 0.464 & $0.89(0.34-2.35)$ & 0.811 \\
\hline
\end{tabular}

\section{Discussion}

This study showed that ethanol, acetone, isopropyl alcohol and PGMEA were four domain VOCs measured in the indoor environment of a TFT-LCD factory. Both ethanol and acetone were identified at the highest levels in the module workstation and isopropyl alcohol and PGMEA were found at the highest levels in the array process. These findings revealed the exposure variance of VOCs levels in the clean room and different exposure pattern as the expectation, which would have the highest level of VOCs in the array or cell process where a lot of organic solvents are used. All of these four VOCs were determined to be far lower than the threshold limit values (TLV) established by the American Conference of Governmental Industrial Hygienists (ACGIH) [15], which is 1000 ppm for short-term exposure level of ethanol, $500 \mathrm{ppm}$ for TLV-time-weighted-average (TWA) of acetone, $200 \mathrm{ppm}$ for TLV-TWA of isopropyl alcohol and 100 ppm for TLV-TWA of PGMEA. However, both the World Health Organization guidelines for indoor air quality [16] and the current indoor quality standards in Taiwan [17] do not take these four components into account. 
In addition, the four dominant VOC sidentified in this study were not consistent with those reported in an early study. $\mathrm{Wu}$ and his colleagues [2] found that PGMEA (average $=252.7 \mathrm{ppb}$ ), butyl acetate (average $=237.0 \mathrm{ppb}$ ), acetone (average $=75.9 \mathrm{ppb}$ ) and isopropyl alcohol (average $=6.7 \mathrm{ppb}$ ) were the four major components of VOCs determined by the Compendium Method TO-17 [18] in a TFT-LCD company in March 2002. This inconsistency might be due to the different sampling approaches and analysis methods employed (i.e., multisorbent tubes and the TO-17 method in the previous study vs. silonite canisters and the TO-15 method in the present study).

The results of this study revealed that exposure to mixed VOCs was associated with elevated blood pressure among TFT-LCD workers. Exposure to ethanol, cyclohexanone and toluene was positively correlated to both resting SBP and DBP. Employees exposed to a total level of ethanol, cyclohexanone and toluene $\geq 2500 \mathrm{ppb}$ were found to have an increased SBP than those exposed to $<2500 \mathrm{ppb}$. Previous epidemiological studies reported that alcohol consumption $>10$ drinks per week (one drink $=12 \mathrm{~g}$ of alcohol) was associated with an elevated SBP of $4.4 \mathrm{mmHg}$ [5], and long-term exposure to toluene with a range of $40-1200 \mathrm{ppm}$ [8] or a median of $25 \mathrm{ppm}$ [9] increased SBP in printing workers. Animal studies in rats showed that ethanol exposure caused an increase in vasopressin-induced constriction [6], and a 6.5-mmHg increase in pulmonary artery pressure was observed after exposure to $210 \mathrm{mg} / \mathrm{m}^{3}$ cyclohexanone after $1 \mathrm{~h}$ [7]. Even though the level of VOCs exposure measured in the present study was obviously lower than that used in the past (human or animal) studies, the findings provided empirical evidence that simultaneous exposure to ethanol, cyclohexanone and toluene might be associated with an increased risk of hypertension. Similar results were reported in an occupational epidemiological study that synthetic leather workers exposed to N, $\mathrm{N}$-dimethylformamide (DMF) and toluene with a mean of $5.8 \mathrm{ppm}$ had a significantly higher mean SBP compared with those exposed to less than $0.5 \mathrm{ppm}$ [19].

In contrast, exposure to acetone, isopropyl alcohol and PGMEA was not positively correlated to the resting SBP and DBP in the present study. The combined effect of these three major compounds $(\geq 1250 \mathrm{ppb}$, the third quartile) was not observed to cause the significantly increased risk of prevalent hypertension ( $\mathrm{OR}=1.27 ; 95 \% \mathrm{CI}: 0.21-7.82 ; p=0.799$ ) after controlling for gender, age, total cholesterol level, HDL cholesterol level and regular exercise. Exposure to acetone $>2000 \mathrm{ppb}$ in the module group was found to have a lower risk of prevalent hypertension (OR $=0.63 ; 95 \%$ CI: $0.07-5.86 ; p=0.688$ ) after controlling for confounders and modifiers. This finding was consistent with the results in a previous study that acetone injections lowered the blood pressure in cats and rabbits [20]. The reduced blood pressure by acetone exposure may be from the nephritic system effect [21].

This study observed that exposure to the mixed VOCs greater than a low level of $2500 \mathrm{ppb}$ was associated with the increased SBP. Although each VOC concentration was far lower than the odor detection threshold and no significant associations were found between SBP and DBP, the significant result between exposure to $\geq 2500 \mathrm{ppb}$ of ethanol, cyclohexanone and toluene might reveal the synergistic effect of co-exposed VOCs. Future studies are recommended to confirm this hypothesis.

However, this association was not observed significantly with the risk of hypertension. One of the possible reasons may be that the mixed level of VOCs exposure is too low to pose the greater increase in SBP. The other may be that study subjects are too young to observe the defined case of hypertension. For instance, the average SBP for the array, cell and module groups was $118.3 \mathrm{mmHg}, 124.3 \mathrm{mmHg}$ and $122.2 \mathrm{mmHg}$, respectively. Even exposure to ethanol, cyclohexanone and toluene elevated an SBP of $5.95 \mathrm{mmHg}$, the total SBP after VOCs exposure was rare to reach the criteria of $140 \mathrm{mmHg}$ as a definition of a hypertensive case. This can explain the finding that workers aged $41.6 \pm 9.1$ years with a mean SBP of $132 \pm 16 \mathrm{mmHg}$ exposed to DMF and toluene had a 7.9-fold increased (95\% CI: 0.9-66.3; $p=0.057)$ risk of hypertension compared with the reference group [19].

The cumulative exposure (exposure concentration $\times$ employment duration) was also considered to determine the associations between different exposure groups on resting SBP, resting DBP and the prevalent hypertension. Subjects co-exposed to a cumulative level of ethanol, cyclohexanone and toluene $\geq 8500 \mathrm{ppb}$-year (the third quartile in the distribution of cumulative exposure for 
mixed VOCs) were found to have higher means of SBP $(2.95 \mathrm{mmHg}, 95 \% \mathrm{CI}:-2.77-8.68 ; p=0.309)$ and DBP $(2.19 \mathrm{mmHg}, 95 \% \mathrm{CI}:-1.94-6.31 ; p=0.296)$ and an increased risk of prevalent hypertension $(\mathrm{OR}=1.19 ; 95 \% \mathrm{CI}: 0.39-3.60 ; p=0.761)$ compared with those co-exposed to a cumulative level $<8500$ ppb-year after adjusting for gender, age, total cholesterol level, HDL cholesterol level and regular exercise. However, all results were not observed significantly in statistics (all $p$ values $>0.05$ ). The possible reasons for the non-significant associations might be related to the choice of this threshold or the high variability of cumulative exposure among this study.

This study was strengthened by the performance of comprehensive exposure assessment and environmental sampling to reduce the variability of subjects' exposure to indoor VOCs at work. Such a method reduced information bias from the misclassification of exposure groups based on the use of job titles or working departments [22]. In addition, the recruitment of clean-room workers only might avoid any selection bias arising from behavioral differences in terms of tasks and job stress that could cause variation in the blood pressure measurements. Non-clean-room workers were not invited to be participants in the study protocol because of significant differences in the indoor environment compared with clean-room workers and no VOCs measurements in the non-clean room. The exclusion of non-clean-room workers as a control group in the present study can avoid the bias of healthy worker effect (i.e., healthy subjects stayed in the clean room and unhealthy ones were resigned to the office for health management) and the blue-collar effect (with different working activity and workplace environment).

However, a cross-sectional study design might restrict the causal inference of a relationship between exposure to VOCs and elevated blood pressure. Although all participants had worked in the same environment for about 3 years, their baseline measurements of blood pressure prior to employment were unknown that limited the ability to elaborate upon the increased SBP due to indoor VOCs exposure. A cohort study involving the comparison of potential risk factors and blood pressure with a time interval of two dates (one or even several years) or an experimental design is encouraged to elucidate the causality and to test the findings reported in this study. In addition, environmental VOCs measurements instead of personal VOCs monitoring may generate potential error in exposure estimations for individual subjects. The VOCs data collected in 2007 were not used to address the current field condition in the rapid development of TFT-LCD manufacturing processes. Some important environment factors (e.g., temperature, humidity, blue light and $\mathrm{CO}_{2}$ levels) were not taken into account. Because all subjects worked in the fab of a TFT-LCD manufacturing factory, the temperature and humidity was rigorously controlled at a constant range to avoid the generation of particles that would not produce the difference between groups or subjects. Short-term exposure to blue light has been reported to decrease SBP in healthy subjects [23]. In contrast, exposure to high $\mathrm{CO}_{2}$ levels was reported to be associated with elevated DBP [24]. Furthermore, the small sample sizes in the module, array and cell groups do not have sufficient power to detect the difference in prevalence of hypertension between groups after adjusting for five potential confounders and modifiers. Finally, some occupational hazards related to hypertension, such as workplace noise [25-27] and job stress [28,29], were not evaluated and controlled for in the analyses. The environmental noise levels of array, cell and module were $74.3 \pm 3.7 \mathrm{dBA}, 71.8 \pm 2.0 \mathrm{dBA}$ and $75.5 \pm 3.4 \mathrm{dBA}$, which was less than the occupational exposure of $80 \mathrm{dBA}$ known to be associated with hypertension [25-27], however such noise exposure at work might cause an acute elevation of blood pressure [30]. These unmeasured hazards might contribute to the elevated blood pressure between different VOCs exposure groups.

\section{Conclusions}

Regardless of these limitations in this cross-sectional study, TFT-LCD workers were identified to have the domain VOCs exposure of ethanol, acetone, isopropyl alcohol and PGMEA. Simultaneous exposure to a total level of ethanol, cyclohexanone and toluene above $2500 \mathrm{ppb}$ was associated with an increased SBP among participants. Future epidemiological studies with a 
follow-up and hypothesis-driven design as well as large sample sizes are still necessary to explore the associations between mixed VOCs exposure and hypertension.

Author Contributions: Conceptualization, T.-Y.C. and B.-Y.B.; methodology, T.-Y.C., K.-H.H., and C.-S.L.; software, K.-H.H. and B.-Y.B.; validation, T.-Y.C. and C.-S.L.; formal analysis, T.-Y.C.; investigation, K.-H.H. and C.-S.L.; resources, T.-Y.C.; data curation, T.-Y.C.; writing-original draft preparation, T.-Y.C., K.-H.H. and C.-S.L.; writing-review and editing, B.-Y.B.; supervision, B.-Y.B.; project administration, T.-Y.C. and C.-S.L.; funding acquisition, T.-Y.C. All authors have read and agreed to the published version of the manuscript.

Funding: This research was funded by the National Science Council, Taiwan, grant number NSC 95-2211-E-039-010 and China Medical University, grant number CMU107-Z-04.

Acknowledgments: We thank the National Science Council, Taiwan (NSC95-2211-E-039-010) and China Medical University (CMU107-Z-04) for their financial support of this research. We also want to thank Ruei-Hao Shie for his methodology consultation in the analyses of VOCs concentrations and all individuals who volunteered to participate in this study.

Conflicts of Interest: The authors declare they have no competing financial interests.

\section{References}

1. IMARC Group, Global TFT LCD Panel Market to Reach US\$208.6 Billion by 2024. Available online: https://www.imarcgroup.com/global-tft-lcd-market-worth-us-193-billion (accessed on 29 March 2020).

2. Wu, C.H.; Feng, C.T.; Lo, Y.S.; Lin, T.Y.; Lo, J.G. Determination of volatile organic compounds in workplace air by multisorbent adsorption/thermal desorption-GC/MS. Chemosphere 2004, 56, 71-80. [CrossRef] [PubMed]

3. Lin, Y.C.; Chang, F.T. Optimizing operating parameters of a honeycomb zeolite rotor concentrator for processing TFT-LCD volatile organic compounds with competitive adsorption characteristics. J. Hazard Mater. 2009, 164, 517-526. [CrossRef] [PubMed]

4. Chang, T.Y.; Huang, K.H.; Liu, C.S.; Shie, R.H.; Chao, K.P.; Hsu, W.H.; Bao, B.Y. Exposure to volatile organic compounds and kidney dysfunction in thin film transistor liquid crystal display (TFT-LCD) workers. J. Hazard Mater. 2010, 178, 934-940. [CrossRef] [PubMed]

5. Tobe, S.W.; Soberman, H.; Kiss, A.; Perkins, N.; Baker, B. The effect of alcohol and gender on ambulatory blood pressure: Results from the Baseline Double Exposure study. Am. J. Hypertens. 2006, 19, $136-139$. [CrossRef]

6. Eby, J.M.; Majetschak, M. Effects of ethanol and ethanol metabolites on intrinsic function of mesenteric resistance arteries. PLoS ONE 2019, 14, e0214336. [CrossRef]

7. Thompson-Torgerson, C.S.; Champion, H.C.; Santhanam, L.; Harris, Z.L.; Shoukas, A.A. Cyclohexanone contamination from extracorporeal circuits impairs cardiovascular function. Am. J. Physiol. Heart Circ. Physiol. 2009, 296, H1926-H1932. [CrossRef]

8. Morck, H.I.; Winkel, P.; Gyntelberg, F. Health effects of toluene exposure. Dan. Med. Bull. 1988, 35, $196-200$.

9. Gericke, C.; Hanke, B.; Beckmann, G.; Baltes, M.M.; Kuhl, K.P.; Neubert, D. Multicenter field trial on possible health effects of toluene. III. Evaluation of effects after long-term exposure. Toxicology 2001, 168, $185-209$. [CrossRef]

10. Su, S.B.; Wang, J.N.; Lu, C.W.; Guo, H.R. Reducing urinary tract infections among female clean room workers. J. Womens Health (Larchmt) 2006, 15, 870-876. [CrossRef]

11. U.S. Environmental Protection Agency (USEPA). Compendium Method TO-15: Determination of Volatile Organic Omcpounds (VOCs) in Air Collected in Specially-Prepared Canisters and Analyzed by Gas Chromatography/Mass Spectrometry (GC/MS), 2nd ed.; U.S. Environmental Protection Agency: Cincinnati, OH, USA, 1999.

12. Chang, T.Y.; Lin, S.J.; Shie, R.H.; Tsai, S.W.; Hsu, H.T.; Tsai, C.T.; Kuo, H.W.; Chiang, C.F.; Lai, J.S. Characterization of volatile organic compounds in the vicinity of an optoelectronics industrial park in Taiwan. J. Air Waste Manag. Assoc. 2010, 60, 55-62. [CrossRef]

13. Chang, T.Y.; Liu, C.L.; Huang, K.H.; Kuo, H.W. Indoor and Outdoor Exposure to Volatile Organic Compounds and Health Risk Assessment in Residents Living near an Optoelectronics Industrial Park. Atmosphere 2019, 10, 380. [CrossRef]

14. Rosner, B. Fundamentals of Biostatistics, 6th ed.; Thomson Brooks/Cole: Belmont, CA, USA, 2006. 
15. American Conference of Governmental Industrial Hygienists, Adopted Threshold limit values. In Proceedings of the 2019 Threshold Limit Values (TLV) and Biological Exposure Indices ACGIH, Cinninnati, OH, USA, 5 March 2019; pp. 11-63.

16. World Health Organization. WHO Guidelines for Indoor Air Quality: Selected Pollutants; World Health Organization: Copenhagen, Denmark, 2010.

17. Taiwan Environmental Protection Administration (TEPA). Indoor Air Quality Standard; Taiwan Environmental Protection Administration: Taipei, Taiwan, 2012.

18. U.S. Environmental Protection Agency (USEPA). Compendium Method TO-17: Determination of Volatile Organic Compounds in Ambient Air Using Active Sampling Onto Sorbent Tubes, 2nd ed.; U.S. Environmental Protection Agency: Cincinnati, OH, USA, 1999.

19. Chang, T.Y.; Wang, V.S.; Hwang, B.F.; Yen, H.Y.; Lai, J.S.; Liu, C.S.; Lin, S.Y. Effects of co-exposure to noise and mixture of organic solvents on blood pressure. J. Occup. Health 2009, 51, 332-339. [CrossRef] [PubMed]

20. Morris, N.; Graham, S. Observations on the Action of Acetone. Arch. Dis. Child. 1927, 2, 212-219. [CrossRef] [PubMed]

21. Druilhet, R.E.; Overturf, M.L.; Hinshaw, R.A.; Kirkendall, W.M. Evidence against acetone-soluble renin inhibitors in normal human plasma. Hypertension 1979, 1, 98-105. [CrossRef] [PubMed]

22. Checkoway, H.; Pearce, N.; Kriebel, D. Precision and validity in study design. In Research Method in Occupational Epidemiology, 2nd ed.; Oxford University Press: New York, NY, USA, 2004; pp. 83-121.

23. Stern, M.; Broja, M.; Sansone, R.; Grone, M.; Skene, S.S.; Liebmann, J.; Suschek, C.V.; Born, M.; Kelm, M.; Heiss, C. Blue light exposure decreases systolic blood pressure, arterial stiffness, and improves endothelial function in humans. Eur. J. Prev. Cardiol. 2018, 25, 1875-1883. [CrossRef]

24. Zhang, X.; Wargocki, P.; Lian, Z. Physiological responses during exposure to carbon dioxide and bioeffluents at levels typically occurring indoors. Indoor Air 2017, 27, 65-77. [CrossRef]

25. Chang, T.Y.; Liu, C.S.; Young, L.H.; Wang, V.S.; Jian, S.E.; Bao, B.Y. Noise frequency components and the prevalence of hypertension in workers. Sci. Total Environ. 2012, 416, 89-96. [CrossRef]

26. Chang, T.Y.; Hwang, B.F.; Liu, C.S.; Chen, R.Y.; Wang, V.S.; Bao, B.Y.; Lai, J.S. Occupational noise exposure and incident hypertension in men: A prospective cohort study. Am. J. Epidemiol. 2013, 177, 818-825. [CrossRef]

27. Liu, C.S.; Young, L.H.; Yu, T.Y.; Bao, B.Y.; Chang, T.Y. Occupational Noise Frequencies and the Incidence of Hypertension in a Retrospective Cohort Study. Am. J. Epidemiol. 2016, 184, 120-128. [CrossRef]

28. Gamage, A.U.; Seneviratne Rde, A. Perceived Job Stress and Presence of Hypertension Among Administrative Officers in Sri Lanka. Asia Pac J. Public Health 2016, 28 (Suppl. 1), 41S-52S. [CrossRef]

29. Clays, E.; Leynen, F.; De Bacquer, D.; Kornitzer, M.; Kittel, F.; Karasek, R.; De Backer, G. High job strain and ambulatory blood pressure in middle-aged men and women from the Belgian job stress study. J. Occup. Environ. Med. 2007, 49, 360-367. [CrossRef] [PubMed]

30. Chang, T.Y.; Liu, C.S.; Hwang, B.F.; Hsieh, H.H.; Bao, B.Y.; Chen, C.J.; Wang, V.S.; Lai, J.S. Acute effects of noise exposure on 24-h ambulatory blood pressure in hypertensive adults. J. Hypertens. 2015, 33, 507-514. [CrossRef] [PubMed]

(C) 2020 by the authors. Licensee MDPI, Basel, Switzerland. This article is an open access article distributed under the terms and conditions of the Creative Commons Attribution (CC BY) license (http://creativecommons.org/licenses/by/4.0/). 